\title{
PP011 - Estudo in vivo de atividade anti-radicalar por quantificação de peróxidos cutâneos
}

\author{
In vivo antiradicalar activity trails by skin peroxidies \\ quantification"
}

\author{
Rodrigo Fuscelli Pytel ${ }^{1}$ \\ Jean-Luc Gesztesi ${ }^{4}$
}

\author{
Luciana Villa Nova Silva² \\ Adilson da Costa
}

Almir Storck Nunes ${ }^{3}$

\begin{abstract}
Resumo: Fundamentos - O organismo humano possui eficientes mecanismos de defesa contra os radicais livres. A relação causal observada entre estresse oxidativo e diversos processos degenerativos despertou o interesse para a exploração de diversos antioxidantes.

OBJetivos - Este trabalho propõe um método in vivo para comprovação da eficácia de um novo complexo de alta atividade anti-radicalar (acetato de tocoferila, licopeno e mistura de ácidos clorogênicos rica em ácido caféico). MÉTodos - Neste ensaio, não invasivo e placebo controlado, a medida da taxa de peróxido cutâneo realizou-se em diferentes áreas - três após a incidência da radiação UV, duas tratadas, uma não tratada, e uma não tratada e não irradiada. A presença do peróxido foi detectada pela aplicação de sonda fluorescente em adesivo específico, que retirou uma amostra do estrato córneo dos sítios supracitados. O cálculo da proteção anti-radicalar dá-se em função das unidades fluorimétricas obtidas.

RESULTADOS - Tomando-se como base áreas controles não irradiadas, as áreas irradiadas e tratadas com o complexo estudado apresentaram concentrações $116 \%$ menores $(\mathrm{p}=0,02 \%)$ de peróxidos cutâneos, com significância estatística em relação às áreas apenas irradiadas. Já as áreas irradiadas e tratadas com o placebo apresentaram concentrações apenas $49 \%$ menores $(p=0,501)$, o que não é estatisticamente significativo em comparação às áreas irradiadas.

CONCLUSÃo - Os resultados obtidos indicam que o complexo estudado possui significativa capacidade protetora da pele contra a ação de radicais livres formados a partir da exposição solar.

Palavras-chave: Acetato de tocoferila; Ácido cafeico; Ácido clorogênico; Antioxidantes; Envelhecimento da pele; Fluorimetria; Licopeno; Radicais livres
\end{abstract}

\begin{abstract}
BACKGROUND - Our organism has important defense mechanisms against free radicals. The causal relationship observed among the oxidative stress and degenerative problems in humans, are getting attention for the exploration of antioxidant agents.

OBJECTNES - This study proposes an in vivo methodology for proving the efficacy of a new bigh-activity antioxidant complex (tocopheryl acetate, licopene and a pool of chlorogenic acids rich in cafeic acid).

METHODS - In this non-invasive and placebo controlled assay, the measure of the peroxide rates was performed in different areas, three after UV radiation, two treated, one non-treated, and an other non-treated and nonirradiated. The peroxide presence was detected through a fluorescent probe on samples stripped form the sites above mentioned. The free-radical scavenger activity is calculated through the fluorimetry results.

RESULTS - Based on non-irradiated areas data's, the irradiated and complex-treated areas presented skin-peroxide concentration $116 \%$ lower, statistically significant $(p=0,02 \%)$ compared to the non-treated irradiated areas. Although, placebo-treated irradiated areas presented skin-peroxide concentration 49\% lower, a nonstatistically significant rate $(p=0,501 \%)$ compared to the irradiated areas.

CONCLUSION - The results indicate that studied-complex, have significant skin-protective action against the free-radicals, usually formed after sun exposure.

Keywords: Tocopheryl acetate; Cafeic acid; Chlorogenic acid; Antioxidants; Skin aging; Fluorimetry; Licopene; Free radicals
\end{abstract}

\footnotetext{
" Trabalho realizado no Laboratório Dermscan (Lyon, França)

Farmacêutico-bioquímico, Pesquisador III - Natura Inovação e Desenvolvimento de Produtos Ltda.

Farmaceutica-bioquímica (especialização em administração), Gerente de Processos Tecnológicos - Natura Inovação e Desenvolvimento de Produtos Ltda.

Farmacêutico-bioquímico, Especialista III - Natura Inovação e Desenvolvimento de Produtos Ltda.

Doutor em Ciências, Cientista II - Natura Inovação e Desenvolvimento de Produtos Ltda.

Médico dermatologista, Gerente Médico - Natura Inovação e Desenvolvimento de Produtos Ltda.

(C)2005 by Anais Brasileiros de Dermatologia
} 


\section{INTRODUÇÃO}

Sabe-se que o organismo humano possui eficientes mecanismos de defesa contra os radicais livres, caracterizados por um conjunto de enzimas e compostos antioxidantes que mantém essas espécies altamente reativas em concentrações subtóxicas. ${ }^{1}$ Quando ocorre um desequilíbrio entre os processos de produção e destruição das espécies reativas de oxigênio, induzido, por exemplo, pela ação da radiação UV, estabelece-se uma condição em que o ataque oxidativo das biomoléculas é favorecido, o que pode propiciar diversos processos fisiológicos e patológicos, incluindo o envelhecimento cutâneo. ${ }^{2}$ A relação causal observada entre estresse oxidativo, diversas patologias e processos degenerativos em humanos despertou o interesse para a exploração de moléculas com atividade antioxidante, capazes de interferir com a geração dos radicais livres de oxigênio ou com as reações por eles desencadeadas.

Radicais livres de oxigênio são formados nas células eucarióticas aeróbias em passos sucessivos de reduções monoeletrônicas do oxigênio, gerando seqüencialmente os radicais ânion superóxido $\left(02^{-\bullet}\right)$, o peróxido de hidrogênio $\left(\mathrm{H}_{2} \mathrm{O}_{2}\right)$ e os radicais hidroxilas $\left(\mathrm{H} 0^{\bullet}\right)$, como esquematizado abaixo:

$$
\begin{gathered}
\mathrm{O}_{2}+\mathrm{e}^{-} \rightarrow \mathrm{O}_{2} \bullet \\
2 \mathrm{H}_{2}+\mathrm{O}_{2}+\mathrm{e}^{-} \rightarrow \mathrm{H}_{2} \mathrm{O}_{2} \\
\mathrm{H}_{2} \mathrm{O}_{2}+\mathrm{Fe}^{+2} \rightarrow \mathrm{Fe}^{+3}+\mathrm{HO}^{*}+\mathrm{HO}^{-} \text {(reação de Fenton) }
\end{gathered}
$$

Entre as espécies reativas de oxigênio, o oxidante mais potente é representado pelos radicais hidroxila $\left(\mathrm{HO}^{\circ}\right)$, os quais são capazes de reagir de modo rápido, com praticamente todas as biomoléculas (como lipídeos, proteínas, carboidratos e ácidos nucléicos) levando ao desenvolvimento da toxicidade celular. ${ }^{3,4}$ Portanto, substâncias capazes de reagir com os radicais hidroxila, ou de impedir o prosseguimento de suas cadeias de reações radicalares, constituem valiosos elementos na proteção antioxidante dos sistemas biológicos. Tais substâncias são genericamente denominadas agentes seqüestradores de radicais livres.

O presente trabalho propõe a utilização de um método in vivo, placebo controlado, como ferramenta da comprovação da eficácia de um novo complexo de alta atividade antioxidante, composto por acetato de tocoferila, licopeno e mistura de ácidos clorogênicos rica em ácido caféico, incorporados a uma fórmula base. O método in vivo utilizado para comprovação da atividade antioxidante em humanos é teste não invasivo, que avalia o estresse oxidativo celular e a porcentagem de captura de radicais livres cutâneos gerados a partir da indução por radiação ultravioleta. Em especial, a ação da radiação UV (A+B) sobre lipí- deos cutâneos leva à formação de peróxidos (Figura 1), que induzem, em cascata a formação de mais radicais livres, de acordo com a reação de Fenton. ${ }^{5}$

A presença do peróxido é detectada em adesivo específico que retira uma amostra do estrato córneo de sítios localizados nas costas dos voluntários. A análise desses adesivos utiliza uma sonda fluorescente na presença de peróxido (Figura 2), e o cálculo da porcentagem de proteção anti-radicalar se dá em função das unidades de fluorimetria obtidas e estatisticamente analisadas. ${ }^{6}$

\section{MATERIAL E MÉTODOS Voluntários}

Todos os procedimentos experimentais envolvendo voluntários seguiram rigorosamente os padrões estabelecidos na Declaração de Helsinque em Boas Práticas Clínicas, relacionados à proteção de voluntários envolvidos em pesquisas biomédicas, e a todos os voluntários foi reservado o direito de abandonar o estudo a qualquer momento e por qualquer motivo.

As composições estudadas contaram com dados provenientes de nove diferentes voluntários, caucasianos, saudáveis, entre 18 e 35 anos de idade, e de fototipos II e III, selecionados de acordo com critérios de exclusão abaixo mencionados:

- mulheres grávidas ou lactantes,

- doentes graves ou crônicos,

- pacientes sob tratamento tópico ou sistêmico à base de:

- antiinflamatórios e/ou anti-histamínicos ao longo das últimas semanas,

- antitussígenos e/ou corticóides ao longo das últimas semanas,

- retinóides e/ou imunossupressores ao longo dos últimos seis meses,

Figura 1: Formamação de peróxido

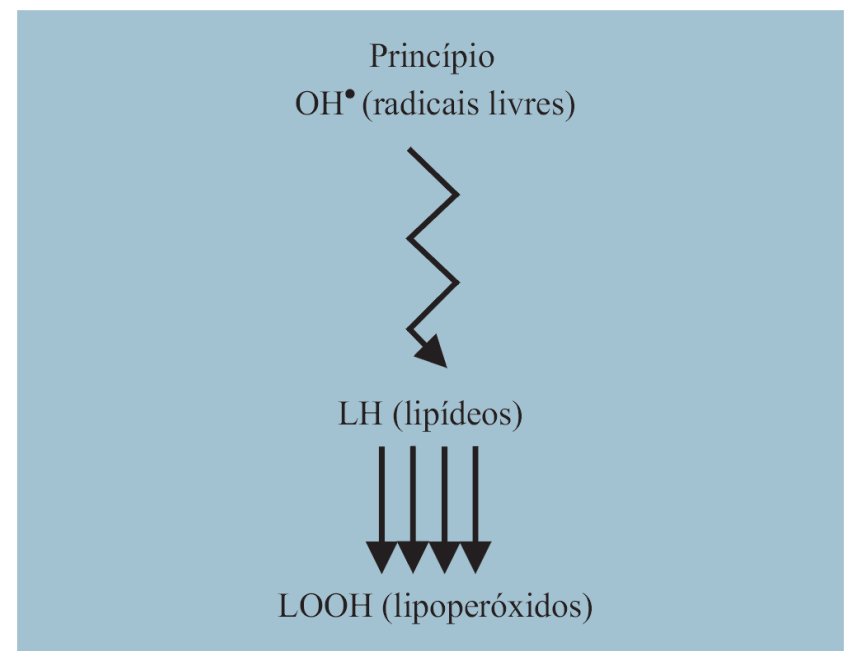


FigurA 2: Fluorescência

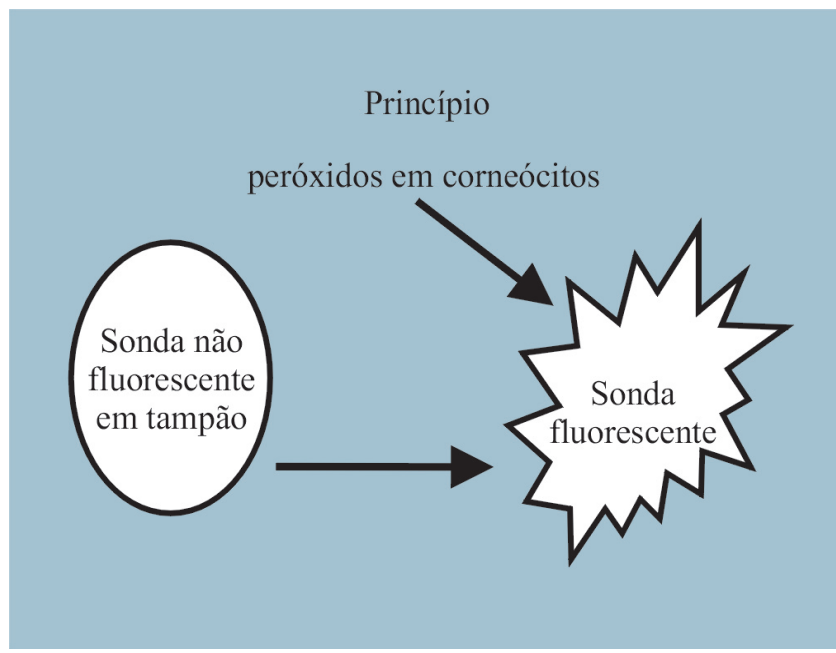

voluntários com doenças sistêmicas,

- pessoas que pararam, iniciaram ou sofreram qualquer alteração em regime de tratamento hormonal (incluindo contraceptivos) no mês anterior ao estudo,

presença de dermatoses no tronco posterior,

- pacientes submetidos a suplementação vitamínica (vitaminas $\mathrm{C}, \mathrm{A}, \mathrm{E}$ ), a tratamentos à base de óligoelementos, paracetamol ou antibióticos há menos de oito dias do estudo ou durante sua realização.

\section{Produtos}

Duas composições de aplicação tópica (Tabelas 1 e 2) foram avaliadas de acordo com o delineamento experimental proposto, diferindo entre si apenas na presença do complexo de alta atividade antioxidante em estudo.

\section{Protocolo de irradiação}

Definiram-se as áreas cutâneas no tronco posterior dos voluntários:

- não irradiada e não tratada (área coberta durante a irradiação),

- irradiada e não tratada,

- irradiada e tratada (para cada produto a ser estudado).

Uma lâmpada do tipo Helarium, fonte padrão de radiação UV $(A+B)$, foi utilizada para induzir a formação de radicais livres cutâneos (Figura 3).

Aplicou-se radiação UV (UVA+UVB) nessas áreas com doses padrão determinadas de $390 \mathrm{~mJ} / \mathrm{cm}^{2}$ e $880 \mathrm{~mJ} / \mathrm{cm}^{2}$, dimensionadas de acordo com o fototipo do paciente.

\section{Protocolo de aplicação}

Cada aplicação utilizou uma dose de $2 \mathrm{~mL} / \mathrm{cm}^{2}$ nas áreas determinada como "irradiadas e tratadas". A
TABela 1: Formulação base (placebo)

\begin{tabular}{lc} 
Componente & Percentual \\
\hline água desmineralizada & qsp. 100,00 \\
EDTA dissódico & 0,10 \\
carbômero & 0,35 \\
goma xantana & 0,20 \\
glicerina & 5,00 \\
benzoato de alquila C12-15 & 12,50 \\
estearil dimeticone & 1,00 \\
dicaprilil carbonato & 2,00 \\
dimeticona e trimetilsiloxissilicato & 1,50 \\
copoliol dimeticone metil éter & 0,50 \\
cetil fosfato de potássio & 2,00 \\
água desmineralizada & 3,00 \\
trietanolamina & 0,50 \\
ciclometicona & 2,00 \\
ciclometicona e dometiconol & 1,00 \\
cocoato de PEG-5 e dicocoato & \\
de PEG-8 e iodopropinil & \\
butilicarbamato e PEG-4 & \\
enoxietanol & 0,20 \\
&
\end{tabular}

TABela 2: Formulação com complexo estudado

\begin{tabular}{|c|c|}
\hline Componente & Percentual \\
\hline Formulação Base & qsp. 100,00 \\
\hline $\begin{array}{l}\text { Mistura de ácidos clorogênicos, } \\
\text { rica em ácido cafeico, licopeno extraído } \\
\text { do tomate de tocoferila }\end{array}$ & 0,50 \\
\hline
\end{tabular}

primeira aplicação padronizada foi feita imediatamente após irradiação (T0), uma segunda aplicação padronizada foi realizada após duas horas de irradiação (T2h), após quatro horas de irradiação (T4h) foi feita uma terceira aplicação padronizada e, finalmente, após seis horas de irradiação (T6h) realizou-se a quarta e última aplicação.

\section{Protocolo de avaliação da presença de peróxido}

No dia seguinte, 24 horas após a irradiação, os voluntários retornam ao laboratório, sem ter lavado as costas, para que se realizasse a medição de peróxido.

Sob condições controladas de temperatura ( $\mathrm{T}$ $\left.=24 \pm 2^{\circ} \mathrm{C}\right)$ e umidade $(\mathrm{U}=40 \mathrm{a} 60 \%)$, a presença de peróxido foi detectada a partir de uma fita adesiva específica que retirou amostras de estrato córneo de cada uma das áreas demarcadas das costas dos voluntários (Figura 4).

Para análise desses adesivos utilizou-se uma sonda que se torna fluorescente na presença de peróxido, após incubação em meio tamponado (Figura 5). ${ }^{7.9}$

A fluorescência foi detectada através do espec- 
FIGURA 3: Espectro lâmpada HELARIUM

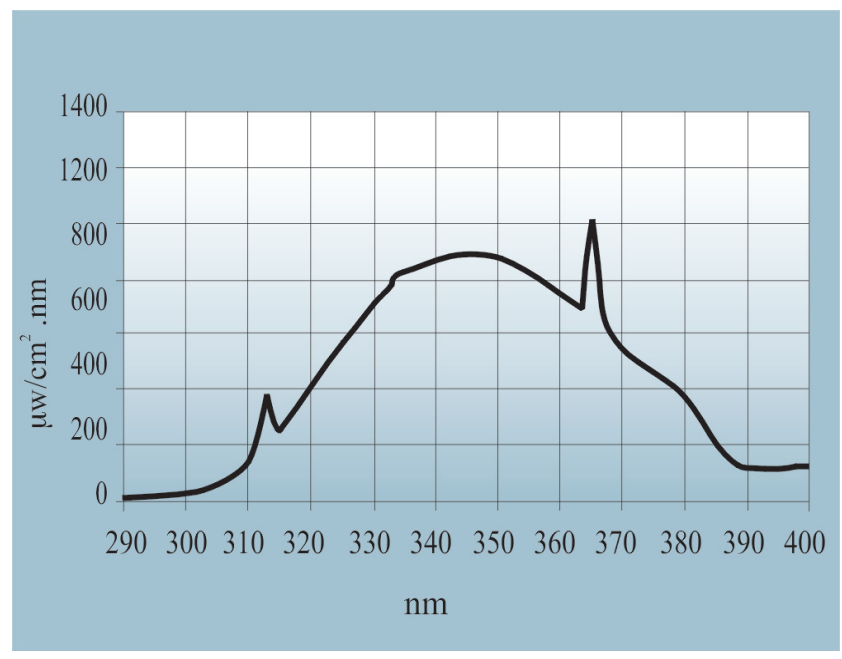

Figura 4: Amostragem

24 horas após a irradiação, dois sucessivos stripings são realizados em cada região das costas dos voliuntários

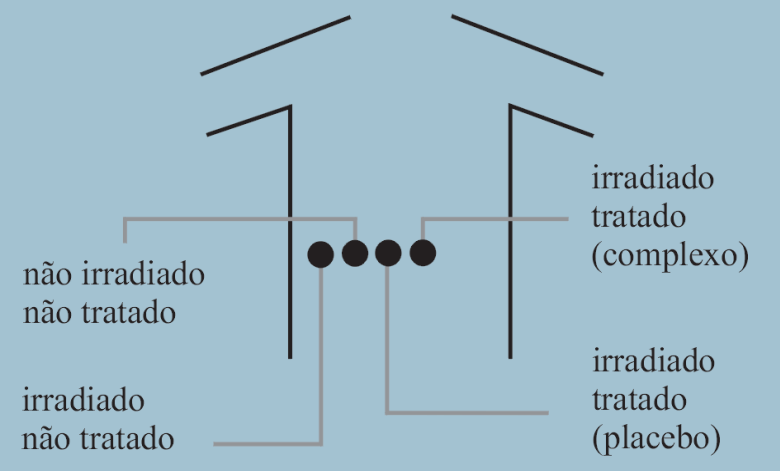

tro-fluorímetro Fluoroscan II $^{\oplus}$ - Labsystem, utilizando-se os comprimentos de onda de excitação $\lambda=$ $485 \mathrm{~nm}$ e o de emissão $\lambda=538 \mathrm{~nm} .{ }^{10}$

Cálculo da porcentagem de proteção anti-radicalar

Deu-se em função média das unidades de fluorimetria obtidas pela comparação dos resultados das áreas irradiadas e tratadas com as obtidas nas áreas irradiadas e não tratadas.

O efeito da radiação ultravioleta foi calculado de acordo com a fórmula abaixo:

Efeito da radiação UV $(\mathrm{D} \%)=($ AIT - ANINT $) /$ ANINT x 100

A eficácia do produto, ou seja, seu poder antiradicalar, (E\%) foi calculada em comparação com a área não tratada, de acordo com a fórmula abaixo:

$\mathrm{E} \%=(($ AINT - AIT $) /($ AINT - ANINT $)) \times 100$ com:

AINT: área irradiada e não tratada
Figura 5: Revelação

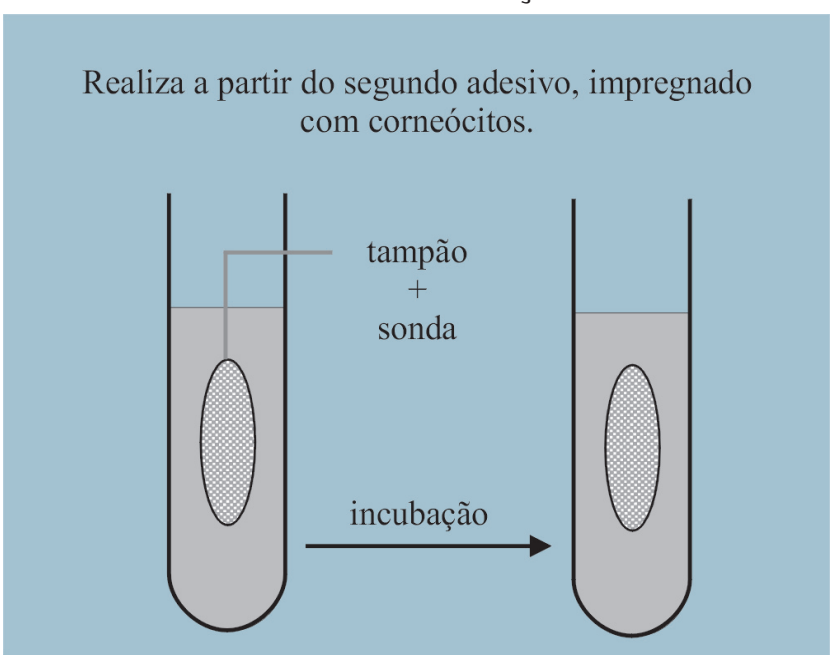

ANINT: área não irradiada e não tratada

AIT: área irradiada e tratada

\section{Análise estatística}

A análise estatística determinou a significância dos resultados obtidos.

Um teste-t pareado, realizado sobre a plataforma EXCEL 9.0 - versão 2000, foi utilizado para realizar a comparação entre os valores obtidos a partir das áreas irradiadas e tratadas e das áreas irradiadas e não tratadas.

\section{RESULTADOS}

A tabela 3, abaixo, apresenta médias e avaliações estatísticas dos resultados obtidos. Esses dados apresentam-se em unidades arbitrárias de fluorescência.

\section{DISCUSSÃO}

Tomando-se como linha base os resultados obtidos a partir das áreas controles não irradiadas, as áreas

TABela 3: Resultados

\begin{tabular}{lcc}
\hline Parâmetro & $\begin{array}{c}\text { Formulação Base } \\
\text { (placebo) }\end{array}$ & $\begin{array}{c}\text { Formulação com o } \\
\text { compelxo estudado }\end{array}$ \\
\hline ANINT & $7,52 \pm 0,71$ & $7,52 \pm 0,71$ \\
AINT & $9,41 \pm 0,84$ & $9,41 \pm 0,84$ \\
AIT & $8,48 \pm 3,99$ & $7,20 \pm 0,81$ \\
D\% & $25,56 \pm 8,02$ & $25,56 \pm 8,02$ \\
E\% & $(p=D, 501)$ & $116 \%(p=0,02)$ \\
\hline
\end{tabular}

ANINT = área não-irradiada e não-tratada

AINT = área irradiada e não-tratada

AIT = área irradiada e tratada

$\mathrm{D} \%$ = efeito da radiação UV

$\mathrm{E} \%=$ poder antiradicalar 
Graficamente tem-se:

Gráficos 1 e 2: Medida do nível de peróxido

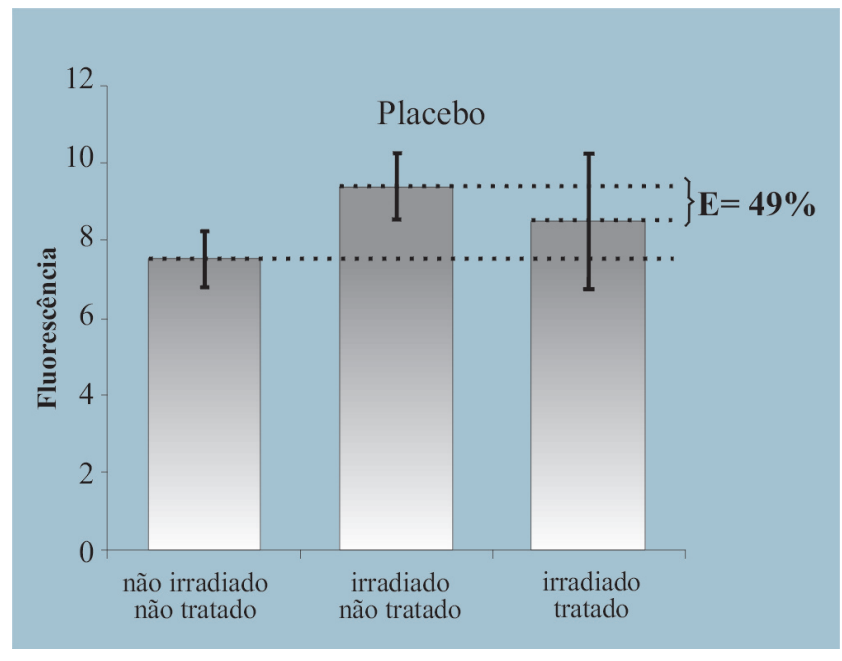

irradiadas e tratadas com o produto contendo o complexo estudado apresentaram concentrações $116 \%$ menores $(p=0,02 \%)$ de peróxidos cutâneos, com significância estatística em relação às áreas apenas irradiadas. Já as áreas irradiadas e tratadas com o placebo apresentaram concentrações apenas $49 \%$ menores $(p=0,501)$, o que não é estatisticamente significativo em comparação às áreas irradiadas. Esses resultados demonstram que apesar da grande dispersão de resultados, inerente à variabilidade natural de resposta do modelo biológico utilizado, a atividade de agentes anti-radicalares topicamente aplicados pode ser comprovada não apenas em ensaios in vitro, mas, também, em humanos, bem como que o complexo anti-radicalar estudado é bom para esse fim quando aplicado topicamente.

\section{CONCLUSÃO}

Os resultados obtidos indicam que a mistura de ácidos clorogênicos, rica em ácido caféico, quando combinada com licopeno, extraído do tomate, e acetado de tocoferila, possui significativa capacidade protetora da pele contra a

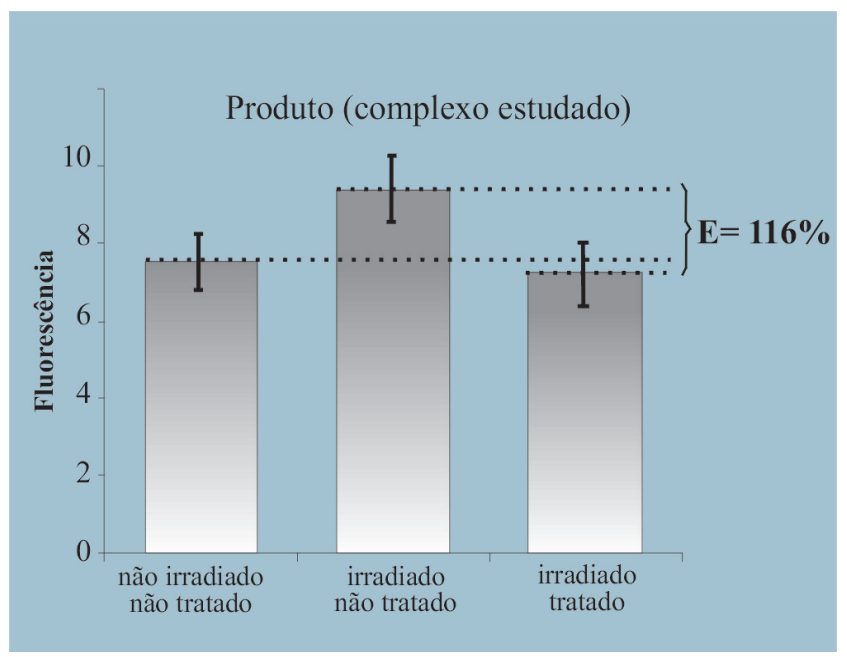

ação de radicais livres formados a partir da exposição solar.

Pode-se concluir, também, que o estudo in vivo de atividade anti-radicalar por quantificação de peróxidos cutâneos é um bom parâmetro para avaliação da capacidade protetora de agentes antioxidantes, constituindo, dessa forma, interessante ferramenta para o desenvolvimento de formulações de aplicação tópica destinadas a auxiliar na manutenção do equilíbrio entre os processos de produção e destruição de radicais livres.

\section{AGRADECIMENTOS}

Estudo patrocinado por Natura Inovação e Tecnologia de Produtos Ltda. (Cajamar, São Paulo). 


\section{REFERÊNCIAS}

1. Cadenas E. Biochemistry of oxygen toxicity. Annu Rev Biochem. 1989; 58:79-110.

2. Harman D. Free radical theory of aging. Mut Res. 1992; 275:257-66.

3. Lenique P. Les radicaux libres. Le mois du dermatologue. 1992;15:34-6.

4. Sies H. Biochemistry of oxidative stress. Angew Chem Int Ed Engl. 1986; 25:1058-71.

5. Morliere P. Ultraviolet A et peau: implications d'éspèces activées de l'oxygène, tendances actuelles et résultats récents. Phatol Biol. 1992; 40:160-8.

6. Lebel C, Ischiropoulos H, Bondy S. Evaluation of probe 2',7'-Dichlorofluorescin as na indicator of reactive oxigen species formation and oxidative stress. Chem Res Toxicol. 1992; 5:227-31.

7. Oyama Y, Hayashi A, Ueha T, Maekawa k. Characterization of 2',7'-Dichlorofluorescin fluorescence in dissociates mammalia brain neurons : estimation of intracelular contend of hidrogen peroxide. Brain Res. 1992; 635:113-7.

8. Rosenkranz AR, Schmaldienst S, Stuhlmeier KM, Chen W, Knapp W, Zlabinger GJ. A microplate assay for the detection of oxidative products 2',7'- Dichloro fluorescindiacetate. J Immunol Met. 1992; 156:39-45.

9. Royall JA, Ischiropoulos $H$. Evaluation of 2',7'Dichlorofluorescin Dihydrorhodamine 123 as fluorescent probes for intracellular $\mathrm{H} 2 \mathrm{O} 2$ in cultured endothelial cells. Arch Biochem Biophys. 1993; 302:348-55.

10. Cathcart R. Detection fo picomol levels of hidroxyperoxides using a fluorescent dichlorofluorescein assay. Anal Biochem. 1983; 134:1-116.

ENDEREÇO PARA CORRESPONDÊNCIA:

Rodrigo Fuscelli Pytel

Rodovia Anbanguera s/n Km 30,5 Bloco A, 07750-000 - Cajamar - SP

Tels.: (11) 4446-2648 / 4446-2730

Fax: (11) 4446-2138

E-mails: rodrigopytel@natura.net ou adilsoncosta@natura.net 